\title{
Study on Power Ultrasound Optimization and Its Comparison with Conventional Thermal Processing for Treatment of Raw Honey
}

\author{
Sandeep Janghu ${ }^{1,2}$, Manab B. Bera ${ }^{2}$, Vikas Nanda ${ }^{2}$ and Ashish Rawson ${ }^{3 *}$ \\ ${ }^{1}$ Department of Food Product Development, IIFPT, MoFPI, Thanjavur, 613005 Tamil Nadu, India \\ ${ }^{2}$ Department of Food Engineering and Technology, SLIET, Longowal, 148106 Sangrur, Punjab, India \\ ${ }^{3}$ Department of Food Safety and Quality Testing, IIFPT, MoFPI, Thanjavur, 613005 Tamil Nadu, India
}

Received: March 17, 2017

Accepted: October 30, 2017

\begin{abstract}
Summary
The present study was done to optimize the power ultrasound processing for maximizing diastase activity of and minimizing hydroxymethylfurfural (HMF) content in honey using response surface methodology. Experimental design with treatment time (1-15 min), amplitude (20-100 \%) and volume (40-80 mL) as independent variables under controlled temperature conditions was studied and it was concluded that treatment time of $8 \mathrm{~min}$, amplitude of $60 \%$ and volume of $60 \mathrm{~mL}$ give optimal diastase activity and HMF content, i.e. 32.07 Schade units and $30.14 \mathrm{mg} / \mathrm{kg}$, respectively. Further thermal profile analyses were done with initial heating temperatures of $65,75,85$ and $95^{\circ} \mathrm{C}$ until temperature of honey reached up to $65^{\circ} \mathrm{C}$ followed by holding time of $25 \mathrm{~min}$ at $65^{\circ} \mathrm{C}$, and the results were compared with thermal profile of honey treated with optimized power ultrasound. The quality characteristics like moisture, $\mathrm{pH}$, diastase activity, HMF content, colour parameters and total colour difference were least affected by optimized power ultrasound treatment. Microbiological analysis also showed lower counts of aerobic mesophilic bacteria and in ultrasonically treated honey than in thermally processed honey samples complete destruction of coliforms, yeasts and moulds. Thus, it was concluded that power ultrasound under suggested operating conditions is an alternative nonthermal processing technique for honey.
\end{abstract}

Key words: power ultrasound, amplitude, diastase activity, HMF, thermal processing

\section{Introduction}

Honey is a supersaturated sugar solution produced by honeybees from nectar of flowers, which they collect, transform and combine with some enzymes of their own, store and leave in comb to ripen and mature (1). Processing of raw honey after harvesting is important from the shelf-life point of view because with the passage of time glucose crystallizes into D-glucose monohydrate crystals and leads to phase separation (2). The upper liquid phase with reduced sugar concentration becomes more susceptible to yeast fermentation and ultimately results in off-flavour or spoilage. The only commercial method that industries follow for delaying crystallization and destruction of existing microorganisms is thermal pasteurization (3). However, heating above $40^{\circ} \mathrm{C}$ affects the quality and causes protein denaturation and deactivation of several enzymes which are mainly responsible for its functional behaviour. Another negative aspect of thermal processing is darkening of honey due to hydroxylmethylfurfural (HMF) formation, which is the breakdown product of fructose in acidic conditions because of nonenzymatic browning or Maillard reaction (4). Light coloured honey usually has milder flavour and higher commercial value than dark coloured honey (5). 
Because of high sugar concentration and acidic $\mathrm{pH}$, honey does not allow the growth of most of the microorganisms. Therefore, only those who withstand such a high carbohydrate concentration and low $\mathrm{pH}$ can be expected to survive in it (6). The major sources of microbial contamination of honey include nectar, pollen, dust, air, honeybee and postharvest handling. Contamination through postharvest handling can be prevented by good hygienic practices, but the rest is not at all possible to control and may lead to human illness under specific conditions. The microbes mainly present in honey include yeast, fungi, coliforms and some aerobic mesophillic bacteria (7). Some researchers reported the presence of several Bacillus species in commercial honey samples in Nigeria (8).

Nowadays consumers are more health conscious and concerned about their diet and food nutritional aspects. This has resulted in research focusing on advanced processing and preservative techniques with reduced impact on the nutrients and overall quality of the food (9-11). That is why nonthermal or minimal processing techniques like power ultrasound are gaining more importance (12). Moreover, ultrasound processing has been identified as a green technology in food industry with varied functions such as effective mixing, faster energy and mass transfer, reduced thermal and concentration gradients, reduced temperature, selective extraction, reduced equipment size, faster response to process extraction control, faster start-up, increased production, elimination of process steps, lower usage of energy, improved extraction using food-grade solvents, and lower production of waste $(13,14)$. Exposing honey to ultrasound at a particular frequency for specific period of time keeps it longer in liquid state by dissolving the existing crystals and delaying further crystallization, extending the shelf life by destroying most of the yeast cells, while the remaining cells lose the ability to grow (2). Ultrasonic treatment at $40 \%$ amplitude and 20 $\mathrm{kHz}$ for 30 min minimally altered the colour, $\mathrm{pH}, \mathrm{HMF}$ content and enzymatic activity, and noticeably improved the mass fractions of phenols, flavonoids in and antioxidant activity of longan, lychee and wildflower honey when compared to the conventional thermal treatment (15).

Response surface methodology (RSM) is a combination of various techniques including statistical and mathematical analyses of one or more independent and dependent variables, which are also known as variables and responses respectively (16). This tool has been successfully used to design and optimize different biotechnological and biochemical processes in relation to food (17). It is very efficient in determining optimum processing conditions and ingredient level, reaching desired minimum and maximum output values and reducing number of experiments, which ultimately leads to time, cost and energy savings (18). Different researchers worked on various food products like snacks (19), biscuit dough (20) and cake (21) using RSM.

Until today no work related to optimization of power ultrasound for honey processing and its comparison with industrial thermal processing of honey has been reported. Thus, the current study was carried out to develop an optimum power ultrasound processing technique for honey, which minimally alters the nutritional and physicochemi- cal properties, by using response surface methodology, and further compared its effects with commercial heat processing protocol for honey.

\section{Materials and Methods}

\section{Honey samples}

The raw honey samples were procured directly from the professional beekeepers of Hisar city, Haryana, India during winter season, in January 2016. The samples of honey were unprocessed and freshly extracted (not older than one week) from the hives kept near the fields of mustard crop. After sampling in dark coloured glass jars, the honey was stored at $4{ }^{\circ} \mathrm{C}$ until analysis (completed within 20 days). Further, all the parameters of honey, i.e. diastase activity, hydroxymethylfurfural (HMF), content, colour changes and microbiological analysis were done on the same day following thermal and ultrasonic treatments.

\section{Thermal treatment of honey}

The raw honey samples were thermally treated as per the conventional method widely applied in food industries, i.e. for $25 \mathrm{~min}$ at $65^{\circ} \mathrm{C}(22)$. The honey samples (50 g) were weighed in $50-\mathrm{mL}$ beakers covered with aluminium foil and immersed in thermostatic water bath (Industrial and Laboratory Tools Corporation, Chennai, India) at 65, 75, 85 and $95^{\circ} \mathrm{C}$ with continuous stirring until the temperature of all samples reached $65^{\circ} \mathrm{C}$. Then the temperature of honey was maintained at $65{ }^{\circ} \mathrm{C}$ for $25 \mathrm{~min}$, after which the samples were drawn and cooled at room temperature for analysis.

\section{Ultrasonic treatment of honey}

Raw honey sample was put in a 100-mL glass beaker and placed into treatment chamber. Ultrasound system (VCX 750 ultrasonic processor; Sonics and Materials, Inc., Newtown, CT, USA) with constant frequency of $20 \mathrm{kHz}$ and $19-\mathrm{mm}$ diameter probe attached with the transducer at fixed pulsation (100\%) was used to treat the sample. The ultrasound treatment of raw honey sample was carried out at different treatment times, amplitude (\%) and volumes for optimization. Temperature of the samples during ultrasound treatment was kept below $40{ }^{\circ} \mathrm{C}$. Overheating was prevented by circulating chilled water around the beaker during treatment inside the chamber. Each experiment was conducted in triplicate to minimize the error and ensure accuracy.

The energy consumption during thermal and ultrasound treatments was calculated using calorimetric method (10) given by the equation:

$$
P=m \cdot C_{\mathrm{p}} \cdot \mathrm{d} T / \mathrm{d} t
$$

where $P$ is the used power (W), $m$ is the mass $(\mathrm{g}), \mathrm{d} T / d \mathrm{t}$ is the change in temperature over time $\left({ }^{\circ} \mathrm{C} / \mathrm{s}\right)$ and $C_{\mathrm{p}}$ is the specific heat of honey $\left(0.60 \mathrm{cal} /\left(\mathrm{g} \cdot{ }^{\circ} \mathrm{C}\right)\right)$.

\section{Moisture analysis of honey}

The refractive index of honey sample was measured at $20^{\circ} \mathrm{C}$ with $\mathrm{RX} 7000 \alpha$ refractometer (ATAGO, Tokyo, Japan) and moisture content was determined using stand- 
ard reference table of honey refractive indices and water content, according to the Harmonized Methods of the International Honey Commission (23). The reading of each sample was done in triplicate.

\section{pH value}

Acidity of honey was checked as per the protocol given in Harmonized Methods of the International Honey Commission (23) using calibrated (at $\mathrm{pH}=4.0$ and 7.0) digital $\mathrm{pH}$ meter ( $\mathrm{pH}$ Tutor, Eutech Instruments, Thermo Fisher Scientific, Singapore). The reading of each sample was done in triplicate.

\section{Colour measurement and total colour difference calculation}

HunterLab ColourFlex EZ, $45^{\circ} / 0^{\circ}$ colour spectrophotometer (Hunter Associates Laboratory, Inc., Reston, VA, USA) was used to measure colour parameters of honey, under the following conditions: illuminant D65, observer $10^{\circ}$ and reflectance mode. The three-dimensional colour space is perceived in $L^{*}, a^{*}$ and $b^{*}$, where $L^{*}$ (luminance) from vertical axis expresses brightness, between complete black to complete white (i.e. $100 \%$ black to $100 \%$ white), and $a^{*}$ and $b^{*}$ axes range from greenness $\left(-a^{*}\right)$ to redness $\left(+a^{*}\right)$ and blueness $\left(-b^{*}\right)$ to yellowness $\left(+b^{*}\right)$ respectively $(24,25)$. The reading of each sample was done in triplicate.

For calculating total colour difference $\left(\Delta E^{*}\right)$ the values of $L^{*}, a^{*}$ and $b^{*}$ were used according to the following formula $(24,25)$ :

$$
\Delta E=\left[\left(L_{0}{ }^{*}-L^{*}\right)^{2}+\left(a_{0}{ }^{*}-a^{*}\right)^{2}+\left(b_{0}{ }^{*}-b^{*}\right)\right]^{1 / 2}
$$

\section{Diastase activity}

Diastase activity was calculated in Schade units (SU) on the basis of $1 \%$ starch hydrolyzed by $\alpha$-amylase enzyme in $1 \mathrm{~g}$ of honey for $1 \mathrm{~h}$ at a temperature below $45^{\circ} \mathrm{C}(23,26)$. Decomposition of starch results in the discolouration of the solution from blue to violet/pink/no colour, which is directly proportional to the amount of decomposed starch. The degree of decomposition mainly depends on the intensity of enzymatic activity. This colour change was observed by UVVis- spectrophotometer (UV-1800; Shimadzu, Tokyo, Japan) at a wavelength of $660 \mathrm{~nm}$ against distilled water as blank. The reading of each sample was done in triplicate.

\section{HMF analysis}

HMF content (in $\mathrm{mg} / \mathrm{kg}$ ) in honey samples was measured using a spectrophotometric direct absorption method (27), where honey solution was filtered after dissolving in Carrez solution (Merck Millipore, Darmstadt, Germany) and then absorption was measured at 284 and $336 \mathrm{~nm}$ (UV-1800; Shimadzu) against the reference solution of honey and 0.2 $\%$ sodium bisulphate (Merck Millipore). The final value (in triplicate for each sample) was obtained using the following equation:

$$
\mathrm{HMF}=\left(\mathrm{A}_{284 \mathrm{~nm}}-\mathrm{A}_{236 \mathrm{~nm}}\right) \cdot 149.7 \cdot 5 \cdot \frac{D}{m}
$$

where $A_{284 \mathrm{~nm}}$ and $A_{336 \mathrm{~nm}}$ are the absorbance of sample solution at 284, and $336 \mathrm{~nm}$ respactively, 149.7 is the constant,
5 is the initial mass of honey sample ( $5 \mathrm{~g}$ ), $D$ is the dilution factor (in case dilution is necessary) and $m$ is the mass of honey sample (in g).

\section{Microbiological analysis}

For determination of microbial flora in the honey, the methodology suggested by Omafuvbe and Akanbi was followed (7). Accordingly, $10 \mathrm{~g}$ of honey sample were mixed thoroughly in 90-mL pre-sterilized maximum recovery diluent (MRD-7658; HiMedia Laboratories Pvt. Ltd., Mumbai, India) under sterile conditions. After appropriate dilutions with MRD, the sample $(100 \mu \mathrm{L})$ was cultured in triplicate using spread plate method. Total aerobic mesophillic bacteria were counted on plate count agar (PCA; HiMedia Laboratories Pvt. Ltd.) after incubation for 48 $\mathrm{h}$ at $(30 \pm 2)^{\circ} \mathrm{C}$. Total coliform count was enumerated on violet red bile glucose (VRBG) agar (HiMedia Laboratories Pvt. Ltd.), incubated for $24-48 \mathrm{~h}$ at $(35 \pm 2){ }^{\circ} \mathrm{C}$. Yeast and fungi were counted on Sabouraud dextrose agar (SDA) supplemented with chloramphenicol (100 mg/L; HiMedia Laboratories Pvt. Ltd.) after incubation period of 3-5 days at $(25 \pm 2)^{\circ} \mathrm{C}$. After the completion of incubation period, all colonies that appeared were counted using digital colony counter (JAINCO 1037; HiMedia Laboratories Pvt. Ltd.) and average number of colonies, multiplied by the dilution factor, was considered for counting. Results were expressed in colony forming unit per g of honey (CFU/g).

\section{Statistical analysis}

The experimental results were analyzed by response surface methodology (RSM) using commercial statistical package, Design Expert v. 10.0.6.0 (Stat-Eease Inc., Minneapolis, MN, USA). A three-factor and three-level central composite design (CCD) with face-centred model was chosen (28) to determine optimum levels of three independent variables, i.e. treatment time (min), amplitude (\%) and volume $(\mathrm{mL})$ against two dependent variables: diastase activity (SU) and HMF content (mg/kg). On the basis of three independent variables, 20 experimental trials were designed including six replicates at centre point. The order of experiments was fully randomized and data were analyzed by multiple linear regression model. A second order polynomial equation was used to express the responses as a function of the independent variables:

$$
\mathrm{Y}_{\mathrm{k}}=\beta_{0}+\sum_{i=1}^{n} \beta_{\mathrm{ki}} \mathrm{X}_{\mathrm{i}}+\sum_{n=1}^{n} \beta_{\mathrm{kii}} \mathrm{X}_{\mathrm{i}}^{2}+\sum_{i=1}^{n-1} \cdot \sum_{j=i+1}^{n} \beta_{\mathrm{kij}} \mathrm{X}_{\mathrm{i}} \mathrm{X}_{\mathrm{j}}
$$

where $Y_{k}$ is the response variable $\left(Y_{1}\right.$ is the diastase activity, $Y_{2}$ is the HMF), $\beta_{0}$ is the constant, $\beta_{\mathrm{ki}}$ is the linear coefficient, $\beta_{\mathrm{kii}}$ is the quadratic coefficient, $\beta_{\mathrm{kij}}$ is the cross product coefficient, $\mathrm{X}_{\mathrm{i}}$ represents coded independent variables $\left(\mathrm{X}_{1}\right.$ is treatment time, $X_{2}$ is amplitude and $X_{3}$ is volume). Statistical significance test was performed using total error criteria with the confidence level of $95 \%$. The significant terms in the model were found by analysis of variance (ANOVA) for all responses and the homogeneity of the variance was checked using Tukey's test. The adequacy was checked on the basis of coefficient of multiple determination $\left(R^{2}\right)$ and adjusted coefficient of determination $\left(\mathrm{R}_{\text {adj }}^{2}\right)$. The numerical optimization of the design 
was used for the simultaneous optimization of responses. The designed goals of each variable and response were selected individually. Treatment time and amplitude range were kept at minimum, and volume was kept at maximum, so that maximum amount of honey can be treated in minimum time with minimum energy, whereas in the case of responses diastase activity was kept at maximum and HMF content at minimum.

\section{Results and Discussion}

\section{Power ultrasound process optimization}

In different ultrasound treatments, the combined effect of time $\left(\mathrm{X}_{1}\right)$, amplitude $\left(\mathrm{X}_{2}\right)$ and volume $\left(\mathrm{X}_{3}\right)$ was studied using RSM and calculations were done at $95 \%$ confidence level. Central composite design with face centred model consisting of 20 experimental trials was designed. The responses of diastase activity and HMF mass fractions obtained after power ultrasound treatment at different independent variable combinations are listed in Table 1. The experimental data were used to calculate various factors of the second order polynomial equation. For any of the terms in the model, large regression coefficient and small p-value indicate a more significant effect on the respective dependent variables. ANOVA for diastase activity and HMF content showed that the resulting quadratic model adequately represented the experimental data, with coefficients of multiple determinations $\left(\mathrm{R}^{2}\right)$ of 0.9601 (Table 2) for diastase activity and 0.9551 (Table 2) for HMF content. The results obtained with the used model indicate that the current study was able to identify optimum processing conditions for freshly harvested raw honey.

\section{Changes in diastase activity}

Diastase activity of honey has been reported to range from 12 to $58 \mathrm{SU}$ with an average value of $38 \mathrm{SU}$. The analysis of variance (ANOVA) confirmed that the diastase activity of honey had highly significant $(\mathrm{p}<0.001)$ negative linear response on treatment time $\left(\mathrm{X}_{1}\right)$ and amplitude $\left(\mathrm{X}_{2}\right)$. The effect of various ultrasonic processing conditions on diastase activity is shown in Figs. 1a-c. It was observed that the increase in the amplitude with time led to decrease in the diastase activity (Fig. 1a). This phenomenon may be due to high energy input; at $100 \%$ amplitude and 8-minute treatment acoustic energy was $39 \mathrm{~W}$, at $60 \%$ amplitude and 8-minute treatment acoustic energy was $8 \mathrm{~W}$, while in thermal treatment it was 4, 14, 18 and $26 \mathrm{~W}$ respectively at 65, 75, 85 and $95^{\circ} \mathrm{C}$ in the $V=60 \mathrm{~mL}$. The enzyme deterioration was higher and the effect was more intense when treatment time increased with amplitude. Other researchers reported similar findings and concluded that with the increase of amplitude (40-80\%) during high power ultrasound treatment the diastase activity was significantly reduced in longan, lychee and wildflower honey samples $(15,29)$. Some researchers $(30,31)$ have reported that the ultrasound increases degradation of natural products during food processing, however, degradation of the metabolites depends on the dosage or energy input; hence a lower input energy may just be sufficient to retain the natural products.

The predicted model for calculating diastase activity of honey was described by polynomial equation:
Table 1. Central composite design showing the effect of treatment time, amplitude and volume on diastase activity of and hydroxymethylfurfural (HMF) content in raw honey samples

\begin{tabular}{|c|c|c|c|c|c|}
\hline \multirow[b]{2}{*}{ Sample } & \multicolumn{3}{|c|}{ Independent variable } & \multicolumn{2}{|c|}{ Dependent variable } \\
\hline & $\begin{array}{c}t / \min \\
\left(X_{1}\right)\end{array}$ & $\begin{array}{c}\text { Amplitude/\% } \\
\left(\mathrm{X}_{2}\right)\end{array}$ & $\begin{array}{c}V / \mathrm{mL} \\
\left(\mathrm{X}_{3}\right)\end{array}$ & $\begin{array}{c}\text { Diastase } \\
\text { activity/SU }\end{array}$ & $\begin{array}{c}w(\mathrm{HMF}) \\
(\mathrm{mg} / \mathrm{kg})\end{array}$ \\
\hline 1 & 15.0 & 60.0 & 60.0 & $28.0 \pm 0.5$ & $40.1 \pm 1.0$ \\
\hline 2 & 1.0 & 20.0 & 40.0 & $57.0 \pm 0.2$ & $13.4 \pm 0.2$ \\
\hline 3 & 8.0 & 60.0 & 60.0 & $35.0 \pm 0.3$ & $34.4 \pm 0.8$ \\
\hline 4 & 8.0 & 60.0 & 40.0 & $32.0 \pm 0.3$ & $36.0 \pm 0.9$ \\
\hline 5 & 8.0 & 60.0 & 60.0 & $30.0 \pm 0.2$ & $29.2 \pm 0.3$ \\
\hline 6 & 15.0 & 100.0 & 80.0 & $32.0 \pm 1.2$ & $34.4 \pm 0.8$ \\
\hline 7 & 8.0 & 20.0 & 60.0 & $55.0 \pm 0.7$ & $15.7 \pm 0.5$ \\
\hline 8 & 8.0 & 60.0 & 60.0 & $30.0 \pm 0.2$ & $29.6 \pm 0.4$ \\
\hline 9 & 1.0 & 100.0 & 80.0 & $43.0 \pm 0.9$ & $22.4 \pm 0.5$ \\
\hline 10 & 8.0 & 100.0 & 60.0 & $20.0 \pm 0.3$ & $39.3 \pm 0.8$ \\
\hline 11 & 8.0 & 60.0 & 60.0 & $30.0 \pm 0.2$ & $29.6 \pm 1.6$ \\
\hline 12 & 8.0 & 60.0 & 60.0 & $30.0 \pm 0.4$ & $29.0 \pm 0.3$ \\
\hline 13 & 15.0 & 20.0 & 40.0 & $50.0 \pm 0.2$ & $18.7 \pm 0.4$ \\
\hline 14 & 15.0 & 20.0 & 80.0 & $55.0 \pm 0.6$ & $14.2 \pm 0.8$ \\
\hline 15 & 8.0 & 60.0 & 80.0 & $38.0 \pm 0.4$ & $26.9 \pm 0.6$ \\
\hline 16 & 15.0 & 100.0 & 40.0 & $12.0 \pm 0.8$ & $48.7 \pm 1.8$ \\
\hline 17 & 8.0 & 60.0 & 60.0 & $30.0 \pm 0.5$ & $29.3 \pm 0.4$ \\
\hline 18 & 1.0 & 20.0 & 80.0 & $58.0 \pm 0.6$ & $12.7 \pm 0.3$ \\
\hline 19 & 1.0 & 60.0 & 60.0 & $45.0 \pm 0.1$ & $19.2 \pm 1.4$ \\
\hline 20 & 1.0 & 100.0 & 40.0 & $42.0 \pm 0.8$ & $23.9 \pm 0.5$ \\
\hline
\end{tabular}

Values are mean of triplicate determinations

$\mathrm{Y}_{1}=31.37-6.80 \mathrm{~A}-12.60 \mathrm{~B}+3.30 \mathrm{C}+4.32 \mathrm{~A}^{2}+5.32 \mathrm{~B}^{2}+$ $2.82 \mathrm{C}^{2}-3.87 \mathrm{AB}+2.88 \mathrm{AC}+1.88 \mathrm{BC}$

where $Y_{1}$ is diastase activity and $A, B$ and $C$ are the coded values of treatment time (min), amplitude (\%) and volume $(\mathrm{mL})$, respectively.

\section{Changes in HMF content}

The maximum HMF content $(48.7 \mathrm{mg} / \mathrm{kg})$ of honey was about 3.8 times higher than the minimum HMF content $(12.7 \mathrm{mg} / \mathrm{kg})$ and the average value was $27.3 \mathrm{mg} / \mathrm{kg}$. The analysis of variance (ANOVA) of the fitted model showed that HMF content of honey had highly significant $(\mathrm{p}<0.001)$ positive linear response on treatment time $\left(\mathrm{X}_{1}\right)$ and amplitude $\left(\mathrm{X}_{2}\right)$ during power ultrasound processing and significant $(\mathrm{p}<0.05)$ negative linear response on volume $\left(\mathrm{X}_{3}\right)$. This indicates that increase in treatment time and amplitude leads to the increase of the HMF content in honey. The 3D response surface plots in Figs. 1d-f, show the effect of ultrasonic processing conditions on HMF content of honey. Ultrasound treatment has been reported to form free radicals in the medium (32). Hence, the stronger the ultrasound treatment, the more free radicals are formed, which in turn may lead to the formation of HMF. Moreover, HMF formation is accelerated when the amplitude is increased from 40 to $80 \%$ (10). Increased amplitude leads to increase in the temperature of honey 
Table 2. Regression coefficients $\left(R^{2}\right)$ of second order polynomial and their significance for diastase activity and hydroxymethylfurfural (HMF) content after ultrasonic treatment

\begin{tabular}{|c|c|c|c|c|c|c|}
\hline \multirow{2}{*}{ Source } & \multicolumn{3}{|c|}{ Diastase activity } & \multicolumn{3}{|c|}{ HMF content } \\
\hline & Coeff. value & F-ratio & $\mathrm{p}$-value & Coeff. value & F-ratio & $\mathrm{p}$-value \\
\hline $\mathrm{X}_{0}$ & $31.37^{* * n}$ & 26.76 & $<0.0001$ & $30.86^{\circ o w}$ & 19.14 & $<0.0001$ \\
\hline $\mathrm{X}_{1}$ & $-6.80^{* \ldots+m}$ & 37.77 & 0.0001 & $6.45^{s+s s}$ & 40.97 & $<0.0001$ \\
\hline $\mathrm{X}_{2}$ & $-12.60^{* * * *}$ & 129.67 & $<0.0001$ & $9.40^{s . s s}$ & 86.99 & $<0.0001$ \\
\hline $\mathrm{X}_{3}$ & $3.30^{* *}$ & 8.89 & 0.0138 & $-3.01^{* *}$ & 8.92 & 0.0137 \\
\hline $\mathrm{X}_{12}$ & $-3.87^{* *}$ & 9.81 & 0.0106 & $3.75^{* *}$ & 11.08 & 0.0076 \\
\hline $\mathrm{X}_{13}$ & $2.88^{* *}$ & 5.40 & 0.0425 & $-2.07^{\circ}$ & 3.39 & 0.0954 \\
\hline$X_{23}$ & $1.88^{\mathrm{ns}}$ & 2.30 & 0.1606 & $-1.33^{\mathrm{ns}}$ & 1.38 & 0.2669 \\
\hline $\mathrm{X}_{1}^{2}$ & $4.32^{\circ}$ & 4.19 & 0.0679 & $-2.26^{\mathrm{ns}}$ & 1.38 & 0.2671 \\
\hline $\mathrm{X}_{2}^{2}$ & $5.32^{* *}$ & 6.35 & 0.0304 & $-4.37^{* s}$ & 5.18 & 0.0461 \\
\hline $\mathrm{X}_{3}{ }^{2}$ & $2.82^{\mathrm{ns}}$ & 1.78 & 0.2113 & $-0.42^{\mathrm{ns}}$ & 0.049 & 0.8300 \\
\hline $\mathrm{R}^{2}$ & & 0.9601 & & & 0.9551 & \\
\hline $\mathrm{R}_{\text {adj }}^{2}$ & & 0.9242 & & & 0.9007 & \\
\hline Adeq. precision & & 19.521 & & & 17.085 & \\
\hline Lack-of-fit & & $4.88^{\mathrm{ns}}$ & & & $3.70^{\mathrm{ns}}$ & \\
\hline
\end{tabular}

"significant at $\mathrm{p}<0.1$, * significant at $\mathrm{p}<0.05, * *$ significant at $\mathrm{p}<0.001, \mathrm{~ns}=$ not significant

and finally enhances the HMF level. Likewise, significant HMF accumulation was observed when temperature and processing time were increased (33). Similar findings were obtained by others with honeydew honey and manuka honey $(34,35)$.

The predicted model for HMF formation in honey was described by polynomial equation:

$$
\begin{aligned}
& Y_{2}=30.86+6.45 A+9.40 B-3.01 C-2.26 A^{2}- \\
& 4.37 B^{2}-0.42 C^{2}+3.75 A B-2.07 A C-1.33 B C
\end{aligned}
$$

where $\mathrm{Y}_{2}$ is $\mathrm{HMF}$ content and $\mathrm{A}, \mathrm{B}$ and $\mathrm{C}$ are the coded values of treatment time (min), amplitude (\%) and volume $(\mathrm{mL})$, respectively.

\section{Ultrasound processing optimization}

The optimum conditions for power ultrasound processing of honey were determined to retain maximum diastase activity with minimal HMF accumulation during processing. Second order polynomial models obtained in the current study were used for both responses, i.e. diastase activity and HMF formation in identifying the optimum processing conditions. In this study, time, amplitude and volume were optimized to 1-15 $\mathrm{min}, 20-100 \%$ and $40-80 \mathrm{~mL}$, respectively. By applying point prediction method, it was determined that the optimum power ultrasound processing conditions are treatment time of 8 min, $60 \%$ amplitude and volume of $60 \mathrm{~mL}$, which corresponds to $8 \mathrm{~W}$ of acoustic energy given to the system. At this point, predicted diastase activity and HMF content were $31.37 \mathrm{SU}$ and $30.86 \mathrm{mg} / \mathrm{kg}$, respectively. Validation of the model was conducted by using the optimized treatment conditions and experimentally obtaining the value of the responses. The predicted (31.37 SU and $30.86 \mathrm{mg} / \mathrm{kg}$ ) and experimental values ( $32.07 \mathrm{SU}$ and $30.14 \mathrm{mg} / \mathrm{kg}$ ) were compared and found to be close, with low error. There- fore, the model obtained in this study could be used for optimization of power ultrasound process for raw honey treatment.

\section{Effects of power ultrasound and thermal treatment on physicochemical parameters}

In the current investigation the comparison between commercial heat processing of honey (i.e. with initial heating at different temperatures and holding time of $25 \mathrm{~min}$ at $65^{\circ} \mathrm{C}$ ) and optimized power ultrasound conditions (treatment time $8 \mathrm{~min}$, amplitude $60 \%$ and volume $60 \mathrm{~mL}$ ) was done and their effects on different quality parameters of honey are described below.

The temperature profile study of thermally treated honey shown in Fig. 2 clearly indicates that speed of temperature increase of honey varies drastically when exposed to different temperature conditions, i.e. heating in water bath at $65^{\circ} \mathrm{C}$ takes more than $21 \mathrm{~min}$ to reach the honey temperature of $65^{\circ} \mathrm{C}$, whereas heating at 75, 85 and 95 ${ }^{\circ} \mathrm{C}$ takes less than 8,7 and 5 min respectively. Achieving honey temperature of $65^{\circ} \mathrm{C}$ and holding time of $25 \mathrm{~min}$ at the same temperature are recommended for complete decrystallization and microbial growth inhibition (23). With longer exposure time qualitative damage is greater. Similar findings were documented stating that heating results in degradation of honey quality, and to calculate the intensity of heat to which honey has been subjected, diastase activity and HMF content are used together as quality parameters (4).

Moisture is the second largest component in honey after sugar and it is one of the deciding factors for shelf life of honey. During processing, some water loss is observed because of high temperature, which is minimal in the case of ultrasonically treated honey because of controlled temperature treatment, but the highest loss, i.e. $0.67 \%$, was ob- 
a)

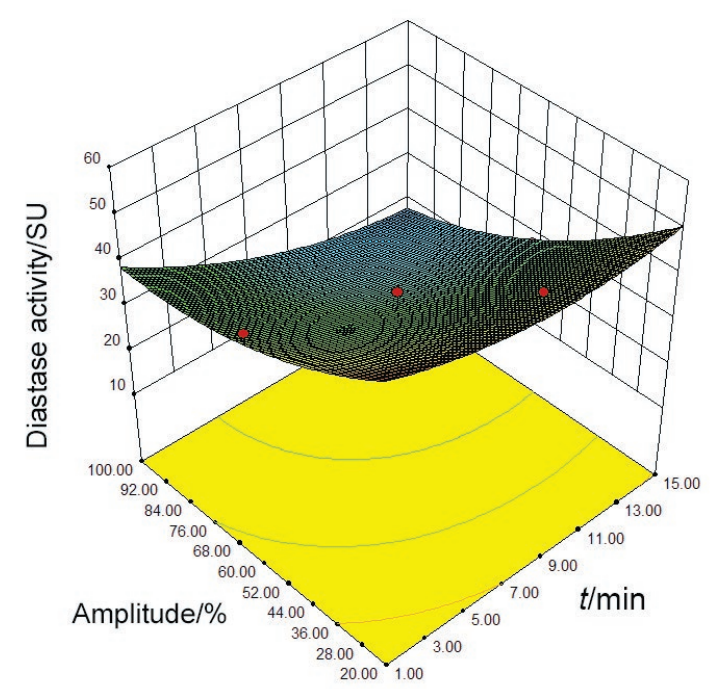

b)

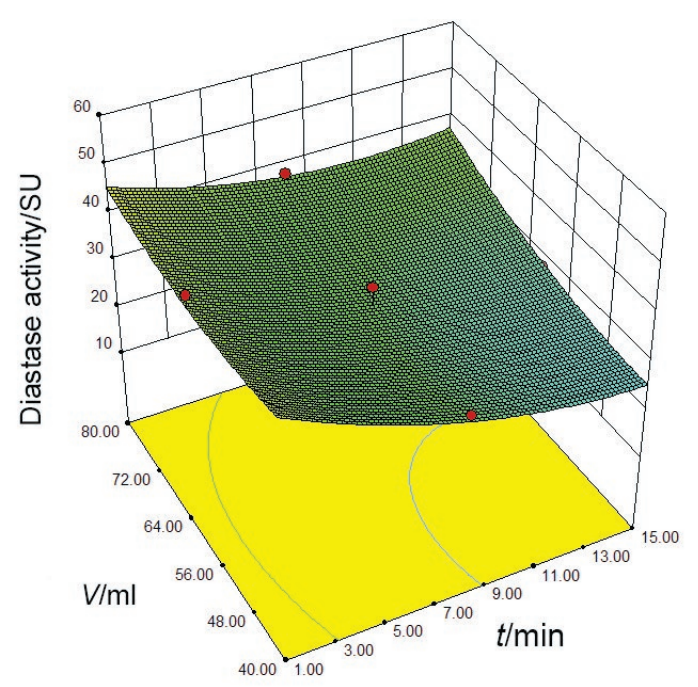

c)

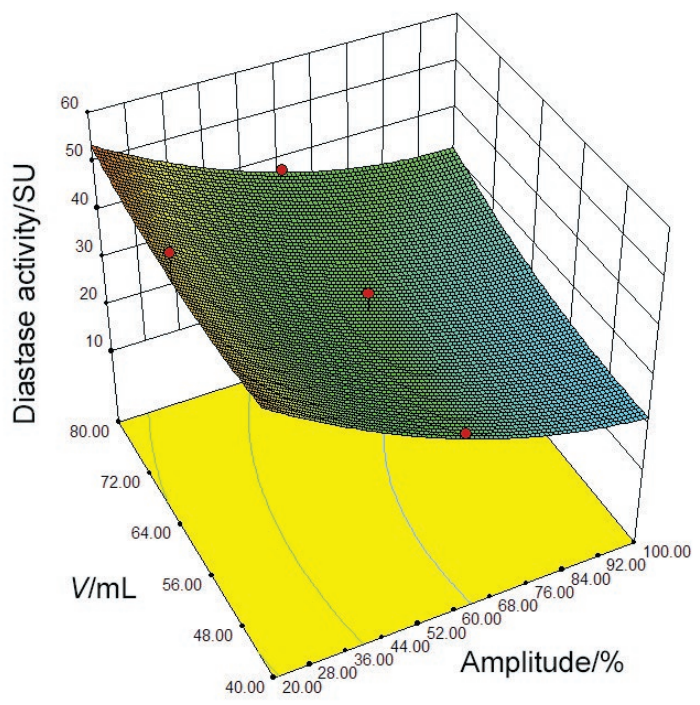

d)

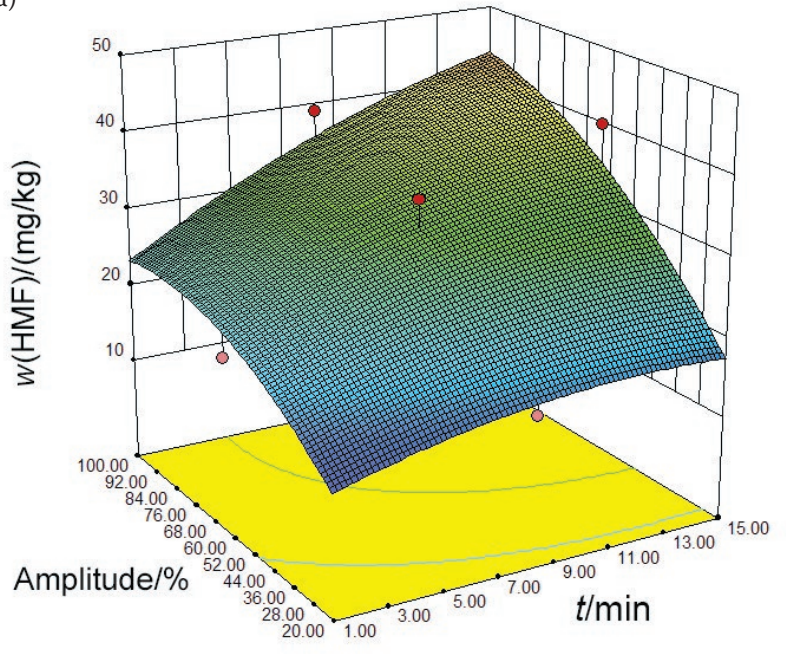

e)

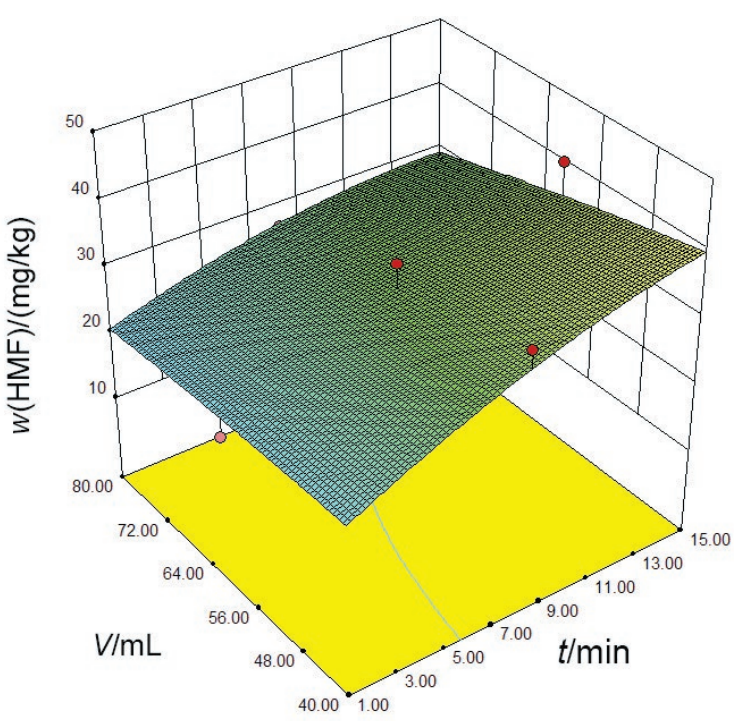

f)

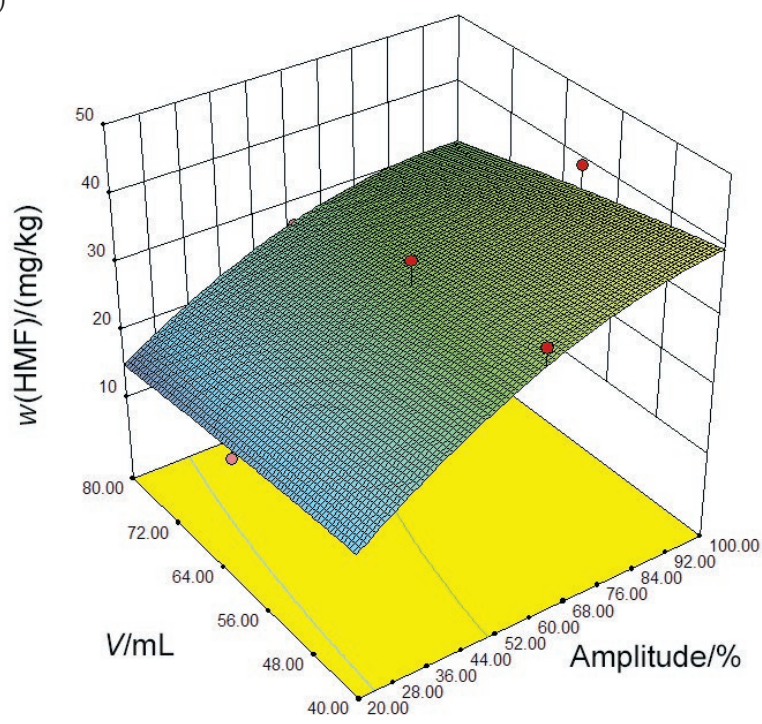

Fig. 1. Response surface plot for: a) diastase activity as a function of treatment time and amplitude at fixed $V=60 \mathrm{~mL}$, b) diastase activity as a function of treatment time and volume at fixed amplitude of $60 \%$, c) diastase activity as a function of amplitude and volume at fixed treatment time $t=8 \mathrm{~min}, \mathrm{~d}$ ) hydroxymethyl furfural (HMF) content as a function of treatment time and amplitude at fixed $V=60 \mathrm{~mL}$, e) HMF content as a function of treatment time and volume at fixed amplitude of $60 \%$, f) HMF content as a function of amplitude and volume at fixed treatment time $t=8 \mathrm{~min}$. SU=Schade unit 


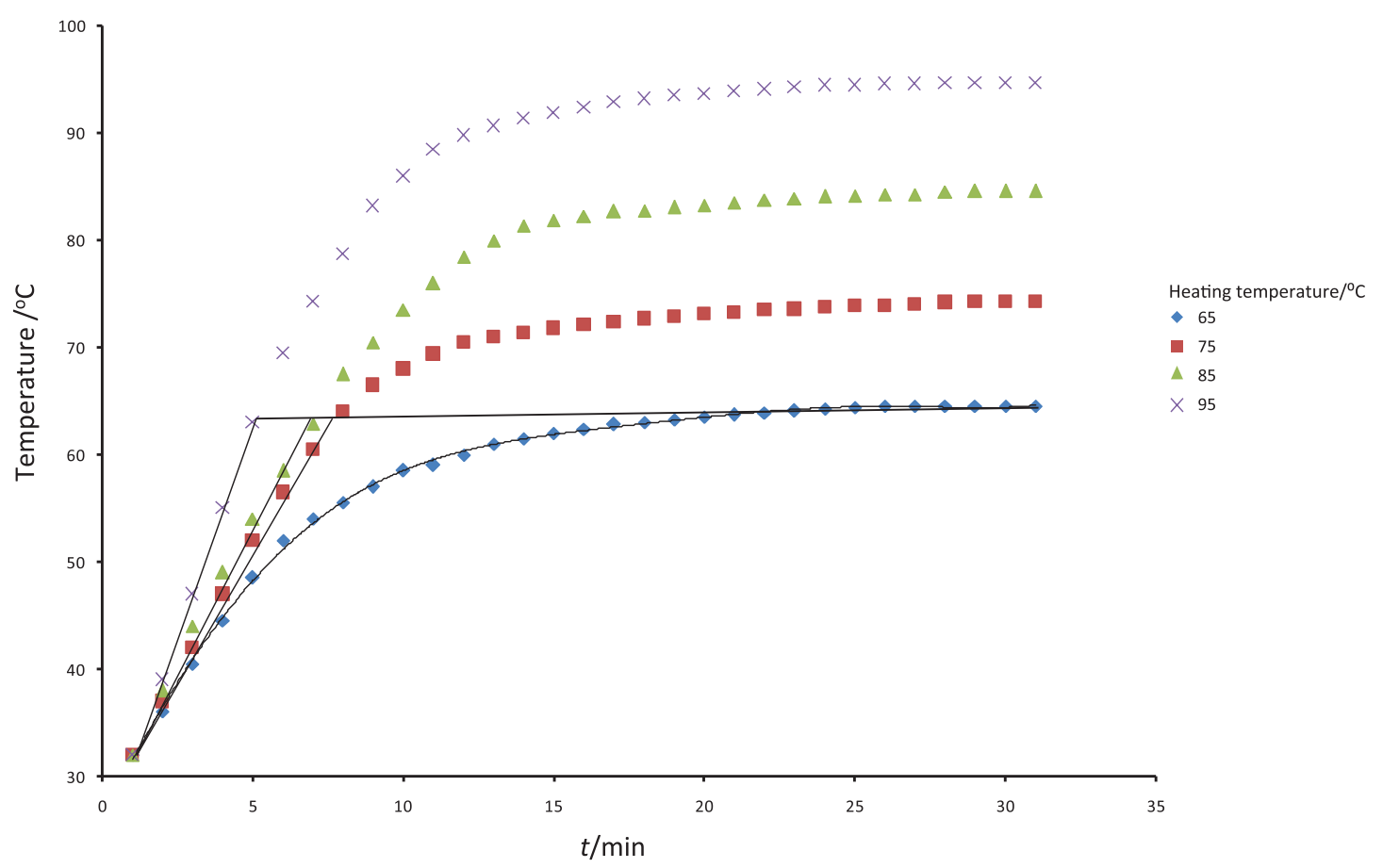

Fig. 2. Temperature profile of thermally treated honey sample from 65 to $95{ }^{\circ} \mathrm{C}$. The line represents the time taken to achieve the temperature of honey of $65^{\circ} \mathrm{C}$ after initial heating at temperatures of $65,75,85$ and $95{ }^{\circ} \mathrm{C}$

served in honey heated at $65^{\circ} \mathrm{C}$. Initial moisture content of raw honey was $16.5 \%$, which was reduced up to $15.8,16.01$, 16.2 and $16.3 \%$ when initial heating temperature was 65 , 75,85 and $95^{\circ} \mathrm{C}$ respectively (Table 3 ). Moisture loss was higher at longer heat exposure time, and it was the highest at $65^{\circ} \mathrm{C}$ (46-minute treatment, i.e. $21 \mathrm{~min}$ arrival time and 25 min holding time) and least at $95^{\circ} \mathrm{C}(30$-minute treatment, i.e. $5 \mathrm{~min}$ to achieve $65^{\circ} \mathrm{C}$ and $25 \mathrm{~min}$ holding time).

Only power ultrasound treatment of honey did not have a significant $(\mathrm{p}>0.05)$ effect on $\mathrm{pH}$ when compared to unprocessed honey, whereas $\mathrm{pH}$ of all thermally treated honey samples significantly decreased. More specifically, greater $\mathrm{pH}$ decrease $(\mathrm{p} \leq 0.05)$ was observed in the samples exposed to heat for a longer period of time. Initial heating at $65^{\circ} \mathrm{C}$ resulted in maximum pH drop, i.e. from 3.52 to 3.35 in raw honey, while initial heating at 75,85 and $95{ }^{\circ} \mathrm{C}$ also resulted in the decrease of $\mathrm{pH}$ in descending order: 3.40, 3.43 and 3.43 respectively when compared to unprocessed honey $(\mathrm{pH}=3.52)$, as shown in Table 3 . The finding was similar to a previous study with conventionally and ultrasonically treated longan, lychee and wildflower honey (15). The decrease in $\mathrm{pH}$ might be because of the increase in hydrogen ion concentration due to heat treatment or because pollen releases organic acids during heating, which also affects the $\mathrm{pH}$ of the final sample (36).

Diastase activity in honey is extensively dependent on floral source of honey and may vary from season to season in the honey from the same flora (37). Diastase activity of unprocessed raw honey was $60 \mathrm{SU}$ and it was reduced to 32.1 SU during ultrasound treatment (Table 3). But during heat processing with different initial temperatures, the loss in diastase activity is higher than in ultrasonically treated

Table 3. Effects of power ultrasound and heat treatments on physicochemical properties of raw honey

\begin{tabular}{ccccccccc}
\hline Treatment & $w$ (moisture)/\% & $\mathrm{pH}\left(\right.$ at $\left.25^{\circ} \mathrm{C}\right)$ & $\begin{array}{c}\text { Diastase } \\
\text { activity/SU }\end{array}$ & $\begin{array}{c}w(\mathrm{HMF}) /(\mathrm{mg} / \\
\mathrm{kg})\end{array}$ & $L^{*}$ & $a^{*}$ & $b^{*}$ & $\Delta E^{*}$ \\
\hline Raw honey & $16.5 \pm 0.2$ & $3.52 \pm 0.05$ & $60 \pm 5$ & $11.9 \pm 0.2$ & $29.1 \pm 0.9$ & $2.21 \pm 0.04$ & $18.5 \pm 0.6$ & \\
Ultrasound & $16.4 \pm 0.2$ & $3.48 \pm 0.02$ & $32.0 \pm 0.1$ & $30.1 \pm 1.3$ & $28.8 \pm 0.3$ & $2.5 \pm 0.3$ & $20.1 \pm 0.5$ & $1.8 \pm 0.1$ \\
Temperature $/{ }^{\circ} \mathrm{C}$ & & & & & & & & \\
\hline 65 & $(15.8 \pm 0.3)^{\mathrm{a}}$ & $(3.35 \pm 0.03)^{\mathrm{b}}$ & $(16.5 \pm 0.3)^{\mathrm{d}}$ & $(48.8 \pm 2.7)^{\mathrm{g}}$ & $(23.8 \pm 1.3)^{\mathrm{j}}$ & $(5.4 \pm 0.5)^{\mathrm{k}}$ & $(25.7 \pm 0.4)^{1}$ & $(9.5 \pm 0.3)^{\mathrm{n}}$ \\
75 & $(16.01 \pm 0.09)^{\mathrm{a}}$ & $(3.40 \pm 0.02)^{\mathrm{bc}}$ & $(21.9 \pm 0.5)^{\mathrm{e}}$ & $(43.6 \pm 0.4)^{\mathrm{h}}$ & $(25.4 \pm 1.3)^{\mathrm{j}}$ & $(4.3 \pm 0.3)^{\mathrm{k}}$ & $(22.96 \pm 0.06)^{\mathrm{m}}$ & $(6.2 \pm 0.5)^{\mathrm{o}}$ \\
85 & $(16.2 \pm 0.7)^{\mathrm{a}}$ & $(3.43 \pm 0.03)^{\mathrm{c}}$ & $(23.3 \pm 0.8)^{\mathrm{f}}$ & $(39.4 \pm 0.9)^{\mathrm{i}}$ & $(25.5 \pm 1.4)^{\mathrm{j}}$ & $(4.2 \pm 0.6)^{\mathrm{k}}$ & $(22.9 \pm 0.5)^{\mathrm{m}}$ & $(6.1 \pm 0.2)^{\mathrm{o}}$ \\
95 & $(16.3 \pm 0.3)^{\mathrm{a}}$ & $(3.43 \pm 0.01)^{\mathrm{c}}$ & $(24.1 \pm 0.2)^{\mathrm{f}}$ & $(38.9 \pm 1.1)^{\mathrm{i}}$ & $(25.5 \pm 0.5)^{\mathrm{j}}$ & $(4.2 \pm 1.1)^{\mathrm{k}}$ & $(22.78 \pm 0.02)^{\mathrm{m}}$ & $(6.0 \pm 0.2)^{\mathrm{o}}$ \\
\hline
\end{tabular}

Mean values in the column followed by different letters are significantly different according to Tukey's test $(\mathrm{p}<0.05)$. Three replicates were performed for each measurement. Ultrasonic treatment was performed at $t=8 \mathrm{~min}$, amplitude $=60 \%$ and $V=60 \mathrm{~mL}$. For each thermal treatment, when temperature of honey reached $65{ }^{\circ} \mathrm{C}$ it was maintained for $25 \mathrm{~min}$ and then the samples were drawn and cooled before analysis. $L^{*}=$ lightness, $a^{*}=$ redness, $b^{*}=$ yellowness, $\Delta E^{*}=$ total colour difference 
honey. The diastase activity decreased from 24.0 to $16.5 \mathrm{SU}$ within the initial heating temperature range from 95 to 65 ${ }^{\circ} \mathrm{C}$. This clearly indicates that heating for longer time depletes more enzymes in honey, which is why the highest loss is at $65^{\circ} \mathrm{C}$ for $46 \mathrm{~min}$, followed by $75^{\circ} \mathrm{C}$ (diastase activity $21.9 \mathrm{SU}$ ), $85^{\circ} \mathrm{C}$ (diastase activity $23.3 \mathrm{SU}$ ) and $95^{\circ} \mathrm{C}$ (diastase activity $24.0 \mathrm{SU}$ ) with total exposure times of 34,32 and $30 \mathrm{~min}$, respectively. In contrast, the diastase activity of all samples after thermal treatment is higher than the level (8 SU) recommended by International Honey Commission (23), which was similar to a previous study where greater loss in diastase activity was reported during heat treatment $\left(90{ }^{\circ} \mathrm{C} / 5 \mathrm{~min}\right)$ than during ultrasound treatment $(40-80 \%$ amplitude/30 $\mathrm{min}$ ) of longan, lychee and wildflower honey (15). Similar results (20-40 \% amplitude/20 kHz/1 h) were obtained for sunflower honey treated with ultrasound (29).

5-Hydroxymethylfurfural (HMF) is a breakdown product of sugar degradation formed during exposure to high temperature under acidic conditions and is used as freshness or thermal damage indicator for honey $(15,37)$. As per our observations, the initial HMF content in unprocessed fresh honey sample was $11.9 \mathrm{mg} / \mathrm{kg}$ (Table 3), which increased in all samples after treatments. However, the increase in HMF content was greater in thermally treated samples than in the ultrasonically treated sample. It increased up to 48.8 $\mathrm{mg} / \mathrm{kg}$ at initial heating temperature of $65^{\circ} \mathrm{C}$ due to longer heat exposure time, which is beyond the acceptable limit of $40 \mathrm{mg} / \mathrm{kg}$ (38), while in the ultrasonically treated sample the HMF increase was minimal, i.e. $30.1 \mathrm{mg} / \mathrm{kg}$, which is because of the temperature control (below $40{ }^{\circ} \mathrm{C}$ ) during power ultrasound treatment. The increased HMF content is directly proportional to the browning index of honey, as shown in Table 3. The accumulation of HMF is mainly dependent on treatment temperature, exposure time and storage (33). Similarly, thermal processing is more effective in producing HMF and decreasing diastase activity in honey than ultrasonication ( $40 \%$ amplitude/30 $\mathrm{min} / 52.63$ ${ }^{\circ} \mathrm{C}$ and $80 \%$ amplitude/ $30 \mathrm{~min} / 75.09^{\circ} \mathrm{C}$ ) (29). Higher rate of HMF formation in honey at $100^{\circ} \mathrm{C}$ than in those heated at 90 and $75^{\circ} \mathrm{C}$ was also reported (34).

Colour of honey is one of the most important acceptability factors for consumers. Light coloured honey is mild in flavour with high commercial value and preferred over dark honey (5). The colour of honey depends on many factors like nectar source, climatic conditions, floral origin, processing technique, etc. In the current investigation, comparative analysis of changes in colour parameters $\left(L^{*}\right.$, $a^{*}, b^{*}$ and $\left.\Delta E^{*}\right)$ of honey due to thermal and power ultrasound treatments was done (Table 3). In all honey samples significant decrease in the lightness was observed when compared to the control. The decrease in lightness was the lowest in ultrasonically treated sample compared to all other thermally processed honey samples. Higher values of redness $\left(+a^{*}\right)$ and yellowness $\left(+b^{*}\right)$ were observed in thermally processed honey sample followed by ultrasonically treated samples than in control. In particular, samples treated at initial temperature of $65^{\circ} \mathrm{C}$ revealed maximum $+a^{*}$ (5.4) and $+b^{*}$ (25.7) values followed by samples treated at initial temperatures of 75,85 and $95^{\circ} \mathrm{C}$. Smaller increase in $+a^{*}(2.5)$ and $+b^{*}(20.1)$ values was observed in ultrasonically treated honey samples than in control sample $\left(+a^{*}=2.21\right.$ and $\left.+b^{*}=18.5\right)$. Similar results were reported in floral honey from Thailand, where maximum increase in $+a^{*}$ and $+b^{*}$ values was observed in thermally processed $\left(90^{\circ} \mathrm{C} / 5 \mathrm{~min}\right.$ ) and the lowest in ultrasonically treated $(80$ and $40 \%$ amplitude/30 min) samples (15). $L^{*}$ value was decreased compared to the control, and the decrease was higher in thermally processed than in ultrasonically processed honey samples because of longer heating time, which caused the formation of more HMF. The results are further supported by significant increase in $+a^{*}$ and $+b^{*}$ parameters after ultrasonic treatment of guava juice (35 $\mathrm{kHz} / 20^{\circ} \mathrm{C} / 30 \mathrm{~min}$ ) and decreased $L^{*}$ value when compared to the control sample (39).

Total colour difference $\left(\Delta E^{*}\right)$ data of both thermally and power ultrasound-treated honey samples in Table 3 further confirms that the colour change is minimum in ultrasonically treated honey (1.8), which is close to the control. However, $\Delta E^{*}$ is more than double in thermally processed honey samples. This clearly indicates that browning reaction occurred due to high temperature treatment and the effect is more severe in samples treated for a longer period of time.

\section{Effects on microbiological qualities}

The microbial counts in raw, thermally processed and power ultrasound-treated honey samples are reported in Table 4. The total aerobic mesophilic bacterial count in raw honey sample was $5.2 \cdot 10^{3} \mathrm{CFU} / \mathrm{g}$, which is close to the value reported by other researchers $(7,40)$. After heat treatment, total aerobic mesophilic bacterial count was reduced to $2.6 \cdot 10^{2} \mathrm{CFU} / \mathrm{g}$ and in ultrasonically treated honey reduction was $1.8 \cdot 10^{2} \mathrm{CFU} / \mathrm{g}$, showing that both thermal and ultrasound treatments were effective in total aerobic mesophilic bacterial reduction in honey. Total coliform count (TCC) was very low, i.e. $0.6 \cdot 10^{5} \mathrm{CFU} / \mathrm{g}$ in raw honey sample, which was completely destroyed during heat treatment for $25 \mathrm{~min}$ at $65^{\circ} \mathrm{C}$ and also no sign of coliforms was found in ultrasonically treated honey samples. Similarly, total fungal count and total yeast count were reduced up to half of their existing level by thermal processing, whereas in ultrasound treatment complete destruction took place.

These results clearly indicate that power ultrasound is more effective than conventional heat processing for microbial inactivation. Microbial inactivation in ultrasonic treatment is due to micromechanical shockwaves which destroy cellular components and ultimately cell lysis takes place. Similar findings were reported in research using ultrasonic treatment $\left(60^{\circ} \mathrm{C} / 9 \mathrm{~min} / 120 \mu \mathrm{m}\right)$ where complete destruction of Escherichia coli, Staphylococcus aureus, Salmonella sp., Listeria monocytogenes and better Bacillus cereus inactivation (3.48 $\log$ CFU/mL) were obtained (41). Thus, the ultrasound processing of honey has significant industrial potential as it could improve the diastase retention in honey as well as decrease the formation of HMF, which in turn retains the colour of honey when compared to thermal processing with the added advantage of microbial inactivation for extended shelf life. Moreover, development in the improved ultrasound systems to date offers better control of treatment conditions which can be easily integrated in industry, and is environmentally friendly. 
Table 4. Mean microbial count of raw, thermally treated and ultrasonically treated honey

\begin{tabular}{ccccc}
\hline \multirow{2}{*}{ Honey sample } & \multicolumn{4}{c}{ N/(CFU/g) } \\
\cline { 2 - 5 } & TAMB & TCC & TFC & TYC \\
\hline Raw & $(5.2 \pm 0.2) \cdot 10^{3}$ & $(0.6 \pm 0.1) \cdot 10^{5}$ & $(0.2 \pm 0.1) \cdot 10^{2}$ & $(3.2 \pm 0.2) \cdot 10^{2}$ \\
Thermally treated & $(2.6 \pm 0.3) \cdot 10^{2}$ & ++ & $(0.1 \pm 0.1) \cdot 10^{2}$ & $(1.00 \pm 0.08) \cdot 10^{3}$ \\
Ultrasonically treated $^{* * *}$ & $(1.8 \pm 0.1) \cdot 10^{2}$ & ++ & ++ & ++ \\
\hline
\end{tabular}

TAMB=total aerobic mesophilic bacteria, TCC=total coliform count, TFC=total fungal count, TYC=total yeast count, $++=$ absence of microbes. "Treatment temperature $T=65^{\circ} \mathrm{C}$, time $t=25 \mathrm{~min}$, **treatment time $t=8 \mathrm{~min}$, amplitude $=60 \%$ and $V=60 \mathrm{~mL}$

\section{Conclusions}

Power ultrasound processing under optimized conditions and controlled temperature could be an alternative to heat processing of honey. In the current research, optimized power ultrasound completely destroyed yeast, mould and coliform bacteria, while the total plate count results were better than in thermally processed honey. Similarly, other physicochemical properties like moisture, $\mathrm{pH}$, diastase activity and HMF formation were least affected under optimum power ultrasound treatment and higher nutritional value was achieved than in thermally processed honey samples. Moreover, ultrasound treatment can lead to a microbially safe honey with minimum deviation in colour and browning index, which can have a better commercial value. However, further research is needed to study the changes during storage at various temperature conditions.

\section{References}

1. Basmaci I. Effect of ultrasound and high hydrostatic pressure on liquefaction and quality parameters of selected honey varieties (MSc. Thesis). Ankara, Turkey: Middle East Technical University; 2010 (in Turkish).

2. Thrasyvoulou A, Manikis J, Tselios D. Liquefying crystallized honey with ultrasonic waves. Apidologie. 1994;25:297-302. https://doi.org/10.1051/apido:19940304

3. Kowalski S, Lukasiewicz M, Bednarz S, Panus M. Diastase number changes during thermal and microwave processing of honey. Czech J Food Sci. 2012;30:21-6.

4. Bogdanov S, Martin P, Lüllmann C. Harmonized Methods of the European Honey Commission. Apidologie. 1997;1-59.

5. Gonzales AP, Burin L, del Pillar Buera M. Colour changing during storage of honeys in relation to their composition and initial colour. Food Res Int. 1999;32:185-91.

https://doi.org/10.1016/S0963-9969(99)00075-7

6. Snowdon JA, Cliver DO. Microorganisms in honey. Int J Food Microbiol. 1996;31:1-26.

https://doi.org/10.1016/0168-1605(96)00970-1

7. Omafuvbe BO, Akanbi OO. Microbiological and physico-chemical properties of some commercial Nigerian honey. Afr J Microbiol Res. 2009;3:891-6.

8. Buba F, Gidado A, Shugaba A. Physicochemical and microbiological properties of honey from North East Nigeria. Biochem Anal Biochem. 2013;2:1-7. https://doi.org/10.4172/2161-1009.1000142

9. Rawson A, Brunton N, Tuohy M. High pressure-temperature degradation kinetics of polyacetylenes in carrots. Food Chem. 2012;133:15-20.

https://doi.org/10.1016/j.foodchem.2011.11.123

10. Rawson A, Tiwari BK, Tuohy MG, O'Donnell CP, Brunton N. Effect of ultrasound and blanching pretreatments on polyacetylene and carotenoid content of hot air and freeze dried carrot discs. Ultrason Sonochem. 2011;18:1172-9.

https://doi.org/10.1016/j.ultsonch.2011.03.009
11. Krishnan VCA, Kuriakose S, Rawson A. Ultrasound assisted extraction of oil from rice bran: A response surface methodology approach. J Food Process Technol. 2015;6:454. https://doi.org/10.4172/2157-7110.1000454

12. Mañas P, Muñoz B, Sanz D, Condón S. Inactivation of lysozyme by ultrasonic waves under pressure at different temperatures. Enzyme Microbial Technol. 2006;39:1177-82. https://doi.org/10.1016/j.enzmictec.2005.11.053

13. Chemat F, Rombaut N, Meullemiestre A, Turk M, Perino S, Fabiano-Tixier AS, Abert-Vian M. Review of green food processing techniques. Preservation, transformation, and extraction Innov Food Sci Emerg Technol. 2017;41:357-77. https://doi.org/10.1016/j.ifset.2017.04.016

14. Chemat F, Rombaut N, Sicaire AG, Meullemiestre A, FabianoTixier AS, Abert-Vian M. Ultrasound assisted extraction of food and natural products. Mechanisms, techniques, combinations, protocols and applications. A review. Ultrason Sonochem. 2017;34:540-60.

https://doi.org/10.1016/j.ultsonch.2016.06.035

15. Chaikham P, Kemsawasd V, Apichartsrangkoon A. Effects of conventional and ultrasound treatments on physicochemical properties and antioxidant capacity of floral honeys from Northern Thailand. Food Biosci. 2016;15:19-26. https://doi.org/10.1016/j.fbio.2016.04.002

16. Cacace JE, Mazza G. Optimization of extraction of anthocyanins from black currants with aqueous ethanol. J Food Sci. 2003;68:240-8.

https://doi.org/10.1111/j.1365-2621.2003.tb14146.x

17. Bansal V, Sharma HK, Nanda V. Optimisation of spray drying process parameters for low-fat honey-based milk powder with antioxidant activity. Int J Food Sci Technol. 2014;49:1196-202. https://doi.org/10.1111/ijfs.12416

18. Režek Jambrak A. Experimental design and optimization of ultrasound treatment of food products. J Food Process Technol. 2011;2:102e.

https://doi.org/10.4172/2157-7110.1000102e

19. Thakur S, Saxena DC. Formulation of extruded snack food (gum based cereal-pulse blend): Optimization of ingredients levels using response surface methodology. LWT - Food Sci Technol. 2000;33:354-61.

https://doi.org/10.1006/fstl.2000.0668

20. Gallagher E, O’Brien CM, Scannell AGM, Arendt EK. Use of response surface methodology to produce functional short dough biscuits. J Food Eng. 2003;56:269-71. https://doi.org/10.1016/S0260-8774(02)00265-0

21. Gan HE, Karim R, Muhammad SKS, Bakar JA, Hashim DM, Rahman RA. Optimization of the basic formulation of a traditional baked cassava cake using response surface methodology. LWT - Food Sci Technol. 2007;40:611-8. https://doi.org/10.1016/j.lwt.2006.05.005

22. Wakhle DM, Phadke RP. Design of honey processing unit. Part I. Indian Bee J. 1995;57:144-6.

23. Bogdanov S. Harmonised methods of the International Honey Commission. Bremen, Germany: International Honey Commission; 2009. 
24. Rawson A, Koidis A, Patras A, Tuohy MG, Brunton NP. Modelling the effect of water immersion thermal processing on polyacetylene levels and instrumental colour of carrot disks. Food Chem. 2010;121:62-8. https://doi.org/10.1016/j.foodchem.2009.12.003

25. Rawson A, Koidis A, Rai D, Tuohy M, Brunton N. Influence of sous vide and water immersion processing on polyacetylene content and instrumental colour of parsnip (Pastinaca sativa) disks. J Agric Food Chem. 2010;58:7740-7. https://doi.org/10.1021/jf100517p

26. Schade JE, Marsh GL, Eckert JE. Diastase activity and hydroxylmethyl-furfural in honey and their usefulness in detecting heat alteration. J Food Sci. 1958;23:446-63. https://dx.doi.org/10.1111/j.1365-2621.1958.tb17592.x

27. White J. Spectrophotometric method for hydroxymethylfurfural in honey. J AOAC Int. 1979;62:509-14.

28. Myers RH, Montgomery DC, Anderson-Cook CM. Response surface methodology: Process and product optimization using design experiments. Hoboken, NJ, USA: John Wiley and Sons, Inc.; 2016

29. Nunta R, Intipunya P. Effects of melting methods on properties of crystallized sunflower honey. Proceedings of the 13th ASEAN Food Conference, September 9-11, 2013. Singapore: Singapore Institute of Food Science and Technology (SIFST)/ASEAN COST/FIFSTA; 2013. pp. 86-92.

30. Achat S, Tomao V, Madani K, Chibane M, Elmaataoui M, Dangles M, Chemat F. Direct enrichment of olive oil in oleuropein by ultrasound-assisted maceration at laboratory and pilot plant scale. Ultrason Sonochem. 2012;19:777-86. https://doi.org/10.1016/j.ultsonch.2011.12.006

31. Jacotet-Navarro M, Rombaut N, Deslis S, Fabiano-Tixier AS, Pierre FX, Bily A, Chemat F. Towards a 'dry' bio-refinery without solvents or added water using microwaves and ultrasound for total valorization of fruit and vegetable by-products. Green Chem. 2016;18:3106-15. https://doi.org/10.1039/C5GC02542G

32. Zhang QA, Shen Y, Fan XH, García Martín JF, Wang X, Song Y Free radical generation induced by ultrasound in red wine and model wine: An EPR spin-trapping study. Ultrason Sonochem.
2015;27:96-101.

https://doi.org/10.1016/j.ultsonch.2015.05.003

33. Gianelli Barra MP, Ponce-Díaz MC, Venegas-Gallegos C. Volatile compounds in honey produced in the central valley of Nuble Province, Chile. Chilean J Agric Res. 2010;70:75-84. https://doi.org/10.4067/s0718-58392010000100008

34. Turhan I, Tetik N, Karhan M, Gurel F, Tavukcuoglu HR. Quality of honeys influenced by thermal treatment. LWT - Food Sci Technol. 2008;41:1396-9. https://doi.org/10.1016/j.lwt.2007.09.008

35. Fauzi NA, Farid MM. High-pressure processing of manuka honey: Brown pigment formation, improvement of antibacterial activity and hydroxymethylfurfural content. Int J Food Sci Technol. 2015;50:178-85. https://doi.org/10.1111/ijfs.12630

36. Chaikham P, Apichartsrangkoon A. Comparison of dynamic viscoelastic and physicochemical properties of pressurised and pasteurized longan juices with xanthan addition. Food Chem. 2012;134:2194-200. https://doi.org/10.1016/j.foodchem.2012.04.056

37. Da Silva PM, Gauche C, Gonzaga LV, Costa ACO, Fett R. Honey: Chemical composition, stability and authenticity. Food Chem. 2016;196:309-23. https://doi.org/10.1016/j.foodchem.2015.09.051

38. Codex Stan 12-1981: Codex standard for honey (Revised codex standard for honey). In: Standards and Standard Methods, vol. 11. Rome, Italy: The Codex Alimentarius Commission, Food and Agricultural Organization of the United Nations (FAO)/World Health Organization (WHO); 2001. pp. 1-8.

39. Cheng LH, Soh CY, Liew SC, Teh FF. Effects of sonication and carbonation on guava juice quality. Food Chem. 2007;104:1396-401. https://doi.org/10.1016/j.foodchem.2007.02.001

40. Tysset C, Rousseau M. Problem of microbes and hygiene of commercial honey. Rev Med Vet. 1981;132:591-600.

41. Herceg Z, Markov K, Sobota Šalamon B, Režek Jambrak A, Vukušić T, Kaliterna J. Effect of high intensity ultrasound treatment on the growth of food spoilage bacteria. Food Technol Biotechnol. 2013;51:352-9. 